\title{
Os intérpretes franceses no Brasil no século $\mathrm{XVI}^{1}$
}

Jean Delisle*

Tradução de Dennys Silva-Reis e Marcos Bagno**

Os intérpretes-residentes formaram uma verdadeira instituição na Nova França (Nouvelle-France, Canadá) durante os séculos XVII e XVIII. Os jovens que escolhiam este ofício se vinculavam por contrato a mercadores de Rouen ou de Saint-Malo e se enredavam nas florestas para viver em simbiose com os indígenas e promover uma propaganda junto aos fornecedores de peles. Tal personagem, no entanto, não foi criado na Nova França, visto que ele já existia no Brasil no século XVI. Navegantes normandos tinham explorado essa parte do mundo antes do descobrimento das ilhas Bahamas por Cristóvão Colombo, em 1492. O

\footnotetext{
${ }^{1}$ Este texto foi publicado originalmente em 1977 na revista Le Linguiste/De Taalkundigi. n. 1-2 em Bruxelas, Bélgica. Agradecemos ao autor por nos ceder os direitos de tradução do presente artigo em português,

* Jean Delisle é professor emérito da Universidade de Ottawa, autor de dezenas de artigos e capítulos de livros sobre história e prática da tradução. Em colaboração com Judith Woodsworth organizou Os tradutores na história, publicado no Brasil em 1998.

** Dennys Silva-Reis é doutorando em Literatura, professor de Língua e Literatura francesas, tradutor e cronista em seu blog Historiografia da tradução no Brasil. Marcos Bagno é professor de tradução do Instituto de Letras da Universidade de Brasília e colaborador do Programa de Pós-graduação em Estudos da Linguagem da Universidade Federal Fluminense.
} 
navegador Jean Cousin, de Dieppe, teria alcançado a foz do Amazonas em 1488. Ignoramos, porém, quase tudo dessas viagens. Os aventureiros guardavam zelosamente seu segredo para não revelar a proveniência dos produtos ou animais exóticos que comerciavam: madeira de tintura ou brasil2 ${ }^{2}$, papagaios (que já sabiam algumas palavras em francês, segundo se conta), peles de onça, macacos, beija-flores, ouro, pimenta do reino e diversas outras mercadorias que eles introduziam nos mercados da Europa. Os navegadores ofereciam em troca aos indígenas peças de tecido, quinquilharias de metal e vidro, pentes, espelhos e outros objetos do gênero:

\begin{abstract}
Entre uma viagem e outra, alguns normandos intrépidos [...] permaneciam entre os selvagens, formavam-se nos hábitos, na língua daqueles povos, e negociavam as relações destes com os comerciantes que falavam francês. Apoderavam-se tão bem do espírito das tribos que os adotavam que os portugueses e os espanhóis jamais puseram os pés naquelas terras sem ter de travar combates encarniçados. Com o tempo, a transformação dos exploradores se completava e os pilotos normandos reencontravam, surpresos, entre alguns selvagens, parentes ou concidadãos considerados mortos ou perdidos nas florestas há muito tempo (SULTE, 1982, p. 50).
\end{abstract}

Houve no Brasil, na segunda metade do século XVI, um importante movimento de colonização por parte de protestantes franceses. Ali se formou uma classe de intérpretes-residentes, comparável à que será criada no século XVII na Nova França. Por seu caráter, seu modo de vida e seus papéis de intermediários e de agentes comerciais junto aos indígenas, os línguas ${ }^{3}$ franco-brasileiros podem ser considerados de algum modo como os "precursores" dos intérpretes e exploradores franco-canadenses. Sem afirmar, contudo, que exista um vínculo direto entre os dois grupos -

\footnotetext{
2 “Toda a Europa ocidental durante a Idade Média chamava brasil as madeiras de tintura e, por um acaso curioso, o nome da produção foi aplicado ao país produtor" (JULIEN, 1946, p. 304-305)

${ }^{3} \mathrm{O}$ autor usa em seu texto o termo truchement, vocábulo com que se designava, em francês, o intérprete no início do período colonial moderno (século XVI). Essa palavra tem a mesma origem do português turgimão (ou dragomano), isto é, o árabe turguman, "intérprete". No entanto, turgimão em português passou a se aplicar ao intérprete que atuava no Oriente. Os intérpretes que se estabeleceram na América portuguesa durante as primeiras fases da colonização eram chamados línguas (no masculino: os línguas), razão por que optamos por traduzir truchement por língua (N. T.).
} 
embora esteja confirmado que alguns intérpretes e viajantes da Nova França passaram uma temporada no Brasil antes de vir para o Canadá -, sabemos que esses homens adotaram a mesma atitude com relação aos indígenas, exerceram seu ofício da mesma maneira e tiveram uma influência política e econômica muito semelhante à dos intérpretes da Nova França.

Os intérpretes do Brasil eram recrutados entre os normandos e os bretões - mas os textos mencionam principalmente os normandos -, que não hesitavam em abandonar a pátria para ir viver no meio dos indígenas. Homens independentes, amantes de aventuras, até mesmo excêntricos, fixavam-se numa tribo, aprendiam a língua de seus anfitriões e se adaptavam por completo aos usos locais. Todos tomavam mulher no lugar e muitos fundavam uma família. Sua bravura, sua determinação e suas habilidades causavam admiração nos brasileiros, que apreciavam no mais alto grau os gestos de arroubo. Os línguas facilmente ganhavam o favor e a simpatia dos indígenas. Seu comportamento contrastava singularmente com o dos conquistadores, que se impunham pelas armas. Ao contrário destes, os intérpretes sabiam fazer-se acolher e, desde os primeiros contatos, criar um clima de amizade. Logo se tornavam os melhores intermediários entre brasileiros e franceses. Compatriotas adotivos dos brasileiros, sua influência crescia dia após dia.

Teria sido fácil, aumentando o número dos intérpretes, fundar rapidamente uma verdadeira colônia naquele lugar. Mas o governo francês de então se preocupava muito pouco com essas questões externas: as guerras com a Espanha e as guerras de religião drenavam todos os seus recursos. O capitão Jean Parmentier, de Dieppe, compreendeu todavia a importância do papel daqueles homens nos primeiros contatos entre franceses e brasileiros:

Se o rei Francisco I quisesse, ainda que minimamente, dar rédea solta aos negociantes franceses [isto é, aos intérpretes], em menos de quatro a cinco anos eles teriam conquistado a amizade e assegurado a obediência dos povos dessas terras novas, e isso sem empregar outras armas além da persuasão e do bom proceder (apud GAFFAREL, 1878, p. 342-343). 
Durante todo o século XVI, entretanto, os línguas franco-brasileiros desempenharam um papel indispensável ao lado dos feitores mantidos em permanência pelos comerciantes nos postos fortificados para organizar sessões de intercâmbio e preparar os carregamentos com destino à Europa. Graças às boas relações que os intérpretes mantinham com as tribos, os indígenas colaboravam de bom grado com os negociantes franceses.

Os línguas exerciam tamanha influência sobre os indígenas que a simples qualidade de francês tinha o valor de um salvo-conduto junto a certas tribos. Os estrangeiros capturados sabiam disso pois, para salvar sua vida, declaravam-se franceses (JULIEN, 1946, p. 182). Ao desembarcar no Brasil, os franceses recebiam todos os cuidados da hospitalidade mais cordial, e há mesmo relatos de que as mulheres "levavam a cortesia ao ponto de oferecer-lhes membros humanos cuidadosamente assados ou escaldados" (GAFFAREL, 1878, p. 342). Em contrapartida, os brasileiros pareciam ter dedicado um ódio profundo aos portugueses e aos espanhóis, que exibiam por toda parte "a insolência da tirania militar" (GAFFAREL, 1878 , p. 158). O grande favor de que gozavam os intérpretes normandos e, por isso mesmo, todos os franceses que chegavam ao Brasil, se devia à sua teoria da assimilação ao contrário.

Os intérpretes franco-brasileiros, no entanto, foram severamente julgados tanto pelas autoridades civis quanto pelas religiosas. Eram acusados de renunciar às suas origens, de viver como libertinos e de abandonar toda prática religiosa. Eis os termos com que um religioso espanhol, José de Anchieta, descreveu o comportamento daqueles homens:

A vida dos franceses que estão neste Rio está não só separada da Igreja católica, mas também se tornou selvagem; vivem como índios, comendo, bebendo, dançando e cantando com eles, pintando-se de suas cores pretas e vermelhas, vestindo-se com uma tanga e, por fim, matando seus adversários segundo o ritual dos mesmos índios, adotando nomes novos como eles, de maneira que nada mais lhes falta senão comer carne humana (apud HAUSER, 1937, p. 103). 
Jean de Léry, natural de Marselha, na França, fez uma avaliação igualmente dura depois de sua passagem pelos assentamentos de Villegaignon:

\begin{abstract}
Alguns intérpretes da Normandia que tinham permanecido oito ou nove anos naquele país, para se acomodar a eles, levando uma vida de ateístas, não se poluíam somente em toda sorte de dissolução e vilanias entre as mulheres e as moças, mas também ultrapassavam os selvagens em desumanidade (JULIEN, 1946, p. 181- 182).
\end{abstract}

Ele chega a afirmar, com horror, ter ouvido alguns deles se vangloriar de ter matado e comido prisioneiros. Portanto, não se deixava de acusar os intérpretes por sua conduta relapsa e sua desumanidade. Um deles tinha incitado indígenas a matar e comer um alemão que, para escapar da morte, se declarava de nacionalidade francesa. Mas não se podia abrir mão daqueles homens. Um exemplo servirá para demonstrar que, sem o concurso dos línguas, todo empreendimento comercial ou qualquer tentativa de assentamento naquela parte do mundo estava fadada ao fracasso. Era preciso contar com aqueles homens. Villegaignon, o valente cavaleiro de Malta encarregado de fundar uma colônia protestante no Brasil, aprendeu uma lição amarga da atitude rígida e intransigente que adotou para com eles.

Na segunda metade do século XVI, a Reforma protestante se estendia rapidamente por toda a Europa. Diante da crescente oposição que enfrentavam na França, os reformados conceberam o projeto de estabelecer uma colônia ultramarina para ali exercer livremente seu culto. Em 12 de julho de 1555, Nicolas Durant de Villegaignon, acompanhado de seiscentas pessoas, partiu da França para o continente sul-americano. Chegando à entrada da baía de Guanabara, decidiu assentar sua gente numa ilha situada a cerca de uma milha da costa e ali construiu um forte que batizou de Forte Coligny.

Desde as primeiras semanas de seu comando, Villegaignon submeteu seus homens - ex-prisioneiros em sua maioria - a uma disciplina rígida, quase militar. Imbuído de princípios morais, proscreveu toda forma de libertinagem e até ameaçou de morte qualquer um que se 
unisse com uma indígena não batizada. Mas os intérpretes franceses estabelecidos de longa data naquela região compartilhavam outro ponto de vista. Tinham-se juntado às brasileiras e viviam livremente entre os naturais; não concebiam poder viver de outro modo senão à maneira da população local.

É fácil compreender que as diretrizes de Villegaignon foram mal recebidas. Ele ia na contramão de hábitos já enraizados no comportamento dos intérpretes. Aliás, um grande número deles tinha se recusado, desde o início, a se sujeitar ao seu comando, preferindo retirar-se para o continente em lugar de se submeter a um chefe tão autoritário. Apesar da partida daqueles homens indispensáveis à realização de sua obra, Villegaignon recusou dar prova de tolerância e amenizar suas exigências. O descontentamento entre os línguas e os colonos crescia dia após dia.

Logo, a situação ficou intolerável e culminou em revolta. Os rebeldes se agruparam e seu chefe foi um intérprete normando, no Brasil havia sete anos. Vivendo abertamente em concubinato com uma brasileira, recebeu a ordem, sob pena de morte, de se casar com a companheira ou de romper imediatamente qualquer relação com ela. Ele não atendeu ao ultimato. Apegado à mulher com quem tinha vários filhos, não quis nem abandoná-la nem se unir a ela pelos laços do matrimônio. As razões exatas de sua recusa permanecem obscuras, mas parece que o conflito se cristalizou em torno deste caso.

Como a exasperação tinha chegado ao ápice, o intérprete fez brilhar aos olhos dos amigos da ilha os encantos da vida na tribo. Não teve nenhuma dificuldade em arrastar para seu lado uns trinta descontentes. Compartilhando a mesma sede de vingança, os rebeldes tramaram um complô de envenenamento contra a pessoa de Villegaignon. Em fevereiro de 1556, no entanto, a conjuração foi descoberta por três escoceses encarregados da guarda pessoal do vice-almirante ${ }^{4}$ :

\footnotetext{
4 “Quando a conspiração foi revelada, o mentor se encontrava no continente e pôde escapar ao castigo que lhe reservava o vice-almirante. Mas quatro de seus companheiros não tiveram a mesma sorte, foram encarcerados e condenados. O chefe da conjuração carregou em sua fuga de vinte a vinte e cinco turgimões." Nicolas Barré apud GAFFAREL, 1878, p. 384.
} 


\begin{abstract}
Soubemos que este (complô) tinha sido conduzido por um língua, o qual fora dado ao dito senhor (Villegaignon) por um gentil-homem normando que acompanhara o dito senhor até este lugar. Esse língua era "casado" com uma mulher selvagem, a quem ele não quis deixar nem tomá-la por esposa. Ora, o dito senhor de Villegaignon, no começo, organizou sua casa como homem de bem e temente a Deus, proibindo que qualquer homem tivesse relação com essas cadelas selvagens se não as tomasse por esposa e sob pena de morte. Aquele língua vivera (como todos os outros vivem) em tamanha abominação de vida epicurista, que é impossível narrar: sem Deus, sem fé nem lei pelo espaço de sete anos. No entanto, fazia-lhe mal abandonar sua puta para viver como homem de bem em companhia de cristãos (apud GAFFAREL, 1878, p. 383).
\end{abstract}

Esse juízo severo e pouco caridoso de Nicolas Barré nos deixa entrever que se tratava sobretudo de um conflito de ordem moral que opunha os línguas a Villegaignon. Mas também é possível acreditar, conforme sugere Charles-André Julien, que a oposição dos línguas talvez não fosse exclusivamente por causas morais, "mas ela marcava a reação dos individualismos ameaçados por uma autoridade que corria o risco de se estender sobre as tribos em detrimento deles" (JULIEN, 1946, p. 202). Aqueles homens não tinham escolhido exercer sua influência sobre os brasileiros ao renunciar à sua origem europeia e ao adotar o modo de vida das populações locais?

Valendo-se de sua ascendência sobre as tribos, os insurgidos se empenharam em deteriorar ao máximo as relações entre os franceses e os autóctones, o que teve graves repercussões:

\footnotetext{
A deserção em massa dos intérpretes normandos foi muito prejudicial aos interesses franceses naquele lugar: ela os privava do concurso de homens habituados ao modo de viver e aos costumes dos brasileiros, que compreendiam a língua e que serviam de intermediários (GAFFAREL, 1878, p. 199-222).
}

A fuga dos línguas não é a única causa do fracasso do cavaleiro de Malta na baía de Guanabara, mas desferiu um golpe mortal no embrião de colônia da Ilha dos Franceses. Ao perder o apoio dos intérpretes, Villegaignon perdia também seu principal meio de ação sobre as tribos e se isolava ainda mais numa região selvagem. Após o fracasso do projeto de 
colonização, os intérpretes normandos prolongaram a presença francesa no Brasil durante quase meio século (TRUDEL, 1963, p. 192), graças à sua habilidade de conquistar a simpatia da população nativa e a alianças lucrativas.

Os historiadores são unânimes ao reconhecer a contribuição fundamental dos línguas no conhecimento da França sobre o Brasil naquela época. Estabelecidos como residentes no país, os intérpretes conheciam bem as crenças, os costumes e as práticas secretas que às vezes se desdobravam por vários anos, como o cativeiro e o sacrifício dos prisioneiros (JULIEN, 1946, p. 384). Eram preciosos agentes de informações etnográficas. Essas informações nos foram transmitidas por Nicolas Barré, secretário de Villegaignon, por Jean de Léry, pelo franciscano André Thevet - que todavia passou apenas três meses no Brasil - e pelo grande Michel de Montaigne, que vivia na Guiana, onde se fixavam muitos aventureiros do Brasil.

O ensaísta teve, como informante, um língua, "um homem que vivera dez ou doze anos neste outro mundo que foi descoberto em nosso século, no lugar em que Villegaignon tomou terra e ao qual chamou França Antártica" (MONTAIGNE, 1965, p. 259). A julgar pela descrição entusiasta que fez do bom selvagem americano (p. 263-264), parece que o língua lhe fizera uma imagem embelezada da realidade. “Ora, acho que não há nada de bárbaro e de selvagem nesta nação" (p. 262), escreve Montaigne. Sua emocionante apologia da vida primitiva nada tem de um quadro repugnante. $\mathrm{O}$ autor dos Ensaios também ficou fascinado pela beleza da língua indígena, de sonoridades doces e agradáveis, "rivalizando com as terminações gregas" (p. 271). Em 1562, teve mesmo a oportunidade de conversar em Rouen com três indígenas do Brasil. Mas, infelizmente, essa entrevista não lhe trouxe todo o prazer que ele esperava devido ao parco desempenho do homem "simples e grosseiro" (p. 261) que lhe serviu de intérprete: “Eu tinha um língua que me acompanhava tão mal e que estava tão impedido de receber minhas imaginações por sua estupidez que não pude obter nenhum prazer" (p. 272).

Ainda que os línguas do Brasil tenham sido homens rudes e intérpretes medíocres, como deixa entrever Montaigne, eles contudo foram 
intrépidos aventureiros e informantes incomparáveis sobre o Brasil. Devemos a eles, além disso, a introdução na língua francesa de numerosas palavras brasileiras que contribuíram para enriquecer e colorir o vocabulário. Ao tomar de empréstimo as denominações locais, vestidas hoje com uma ortografia francesa, eles nos transmitiram os nomes da anta (tapir), do sagui (sagouin), da arara (ara), do tucano (toucan), do caju (acajou), do ananás (ananas), da mandioca (manioc) (GAFFAREL, 1878, p. 346) e tantas outras designações do tupi e do guarani.

Este retrato dos intérpretes franco-brasileiros ficaria incompleto se não mencionássemos que, em suas horas vagas, eles se dedicavam ao adestramento de papagaios "bilíngues", muito requisitados na Europa. Os mais estimados destes pássaros eram chamados no Brasil de ajurus. Jean de Léry recebeu um muito dotado para as línguas, ao que parece: "Ele proferia também tanto [a língua do] selvagem quanto o francês que, sem o ver, alguém seria incapaz de discernir sua voz da de um homem" (GAFFAREL, 1878, p. 78-79). Aquele papagaio tivera um professor de línguas como já não existe hoje em dia...

\section{Referências}

GAFFAREL, Paul. Histoire du Brésil Français au XVI ${ }^{\text {e }}$ siècle. Paris: Maisonneuve frères, 1878.

HAUSER, Henri. “Les Huguenots français au Brésil (1560-1584)”. Bulletin de la Société de l'Histoire du protestantisme français. N. 86. (abril-junho) 1937.

JULIAN, Charles-André. Les français en Amérique pendant la première moitié du XVIe siècle. Paris: PUF, 1946.

MONTAIGNE, Michel. Les essais. Paris: Gallimard, 1965.

SULTE, Benjamin. Les interprètes du temps de Champlain. Section I, 1882. Transactions de la Société royale du Canada. "(Lu le 26 mai 1882)". Reproduction of original in: National Library of Canada. [S.l. : s.n., 1882?] p. 4756.

TRUDEL, Marcel. Les vaines tentatives. Montréal: Fides, 1963. 


\section{Post scriptum dos tradutores:}

O presente artigo pode ser aprofundado com a leitura do seguinte texto:

PERRONE-MOISÉS, B.. “Franceses no Maranhão: Histórias de Intérpretes”. In: PERRONE-MOISÉS, L.. (Org.). Cinco Séculos de Presença Francesa no Brasil. 1ed. São Paulo, SP: EDUSP, 2013.

A autora oferece novos elementos não apresentados por Jean Delisle, bem como propõe uma nova visão dos intérpretes franceses no espaço geográfico do Maranhão.

A história dos intérpretes franceses no Brasil também se tornou ficção:

Rouge Brésil (2001), romance histórico de Jean-Christophe Rufin, que no Brasil foi traduzido por Adalgisa Campos Silva (Vermelho Brasil, 2015), ganhou vários prêmios por descortinar o imaginário francês sobre o Brasil colonial no século XVI, tendo como personagens principais os intérpretes franceses.

O filme Rouge Brésil (2014), Vermelho Brasil na versão brasileira, do cineasta Sylvain Archambault, baseado no romance homônimo, também conta por meio do audiovisual a história desses intermediários da França Antártica.

\section{Resumo}

Antes do início da colonização francesa no Canadá ("Nova França"), houve uma tentativa de fixação de franceses no Brasil, especificamente no Rio de Janeiro (França Antártica), sob o comando de Villegaignon. Para esse empreendimento colonizador, o papel dos intérpretes franco-brasileiros foi essencial, na medida em que estes serviram de intermediários entre os europeus e os povos indígenas.

Palavras-chave: Intérpretes franco-brasileiros; presença francesa no Brasil no século XVI; França Antártica; historiografia da interpretação. 


\begin{abstract}
Before the beginning of French colonisation in Canada ("Nouvelle France") there was an attempt of a French settlement in Brazil, particularly in Rio de Janeiro ("France Antarctique"), under the rule of Villegaignon. For this colonial enterprise, the role of French-Brazilian interpreters was crucial, in that they served as intermediaries between the Europeans and the indigenous peoples.
\end{abstract}

Keywords: French-Brazilian interpreters; French settlement in Brazil in the $16^{\text {th }}$ century; France Antarctique; historiography of interpretation. 